\title{
Adhesive Strength of Paint-on Resins to Crown and Bridge Composites
}

\author{
Takahito KANIE, Hiroyuki ARIKAWA, Koichi FUJII and Seiji BAN \\ Department of Biomaterials Science, Field of Oral and Maxillofacial Rehabilitation, Advanced Therapeutic Course, Kagoshima \\ University Graduate School of Medical and Dental Sciences, 8-35-1 Sakuragaoka, Kagoshima 890-8544, Japan \\ Corresponding author, E-mail:einak@dentb.hal.kagoshima-u.ac.jp
}

Received July 1, 2004/Accepted August 20, 2004

This paper examined the adhesive strength of paint-on resin to crown and bridge composites after soaking in water and thermal-cycling. Three shades of paint-on resin were coated on three kinds of crown and bridge composite under four surface treatment conditions (a combination of sandblaster and pretreatment liquid). These specimens were soaked in water at $37^{\circ} \mathrm{C}$ for 1 day, 1 month, and 1 year, and at $4^{\circ} \mathrm{C}$ and $60^{\circ} \mathrm{C}$ alternatively for 1 -minute periods for 10,000 cycles by thermalcycling machine. The adhesive strengths were obtained by shear test. There were no significant differences among the adhesive strengths of three shades of paint-on resin to three composites after storage $(p>0.05)$. The adhesive strengths to composites with sandblasting showed higher values than those without it $(\mathrm{p}<0.01)$.

Key words: Adhesive strength, Crown and bridge composite, Paint-on resin

\section{INTRODUCTION}

Crown and bridge (crown \& bridge) composites are used as esthetic restorative materials for jacket crowns and facing crowns. Therefore, an excellent color match between the crown \& bridge composite and the tooth is vital to esthetic success. However, color tone of the crown \& bridge composite can be changed by various factors. It can be changed by conditions in the oral cavity, due to consumption of foods and drinks, tobacco, etc. It can also be changed by the finished surface conditions of the crown \& bridge composite ${ }^{1-5)}$. In particular, the thin resin layer makes it difficult to reproduce a matching and stable color tone for the crown \& bridge composite $^{6,7)}$. This is because the thin resin layer reflects the background color. Recently, a light-curing painton resin - which has the selling points of abrasion resistance and color tone stability - has been on the market to solve these problems. This material is first applied to the surface of the crown \& bridge composite or artificial plastic tooth. Then, the following are carried out: last shade adjustment, correction, characterization. To find out more about this resin, we have been studying its resistance to tooth- brush abrasion ${ }^{8,9)}$ and its optical properties ${ }^{10,11)}$.

The aim of this investigation was to evaluate the adhesive strength and durability of paint-on resin. So the adhesive strengths between three kinds of crown \& bridge composite and three shades of painton resin were measured under various surface treatment conditions and storing conditions of test specimens.

\section{MATERIALS AND METHODS}

\section{Materials}

Three kinds of commercial crown \& bridge composite and three shades of paint-on resin were used in this investigation, as shown in Table 1. A pretreatment agent ( $c \&$ b liquid, Heraeus Kulzer Japan, Osaka, Japan) was used to process the test specimens according to the surface treatment conditions given in Table 2.

\section{Test specimens preparation}

The dentin or body paste of the crown \& bridge composites shown in Table 1 was filled into the hole of a stainless steel holder $(20 \times 30 \times 1 \mathrm{~mm}$ with $ø 10$ $\mathrm{mm}$ hole). Subsequently, the enamel or incisal paste

Table 1 Light-curing crown and bridge composites and paint-on resins used in this investigation

\begin{tabular}{lccc}
\hline \multicolumn{1}{c}{ Material } & Shade & Manufacturer & Code \\
\hline Crown and bridge composite & & & \\
Dentacolor Sirius Dentin/Enamel & DA1/EL & Heraeus Kulzer Japan & DS \\
Solidex Body/Incisal & A3B/59 & Shofu & SO \\
Epricord Dentin/Enamel & DA3/E1 & Kuraray Medical & EP \\
\hline Paint-on resin & & \\
Master Palette & A-shade & Heraeus Kulzer Japan & MA \\
& Orange & & MO \\
& Transparent & & MT \\
\hline
\end{tabular}


Table 2 Four surface treatment conditions of cured enamel or incisal crown and bridge composites before painting the paint-on resin

\begin{tabular}{cc}
\hline Surface treatment & Code \\
\hline- & NT \\
Sandblaster treatment & SB \\
Pretreatment agent (c \& b liquid) & PA \\
Sandblaster treatment + Pretreatment agent (c \& b liquid) & SP \\
\hline
\end{tabular}

Table 3 Three conditions of preparing the test specimens for adhesive test

\begin{tabular}{ccccc}
\hline Condition & Composite & Paint-on resin & Surface treatment & \multicolumn{1}{c}{ Conservation } \\
\hline 1 & DS & MA, MO, MT & SP & In water at $37^{\circ} \mathrm{C}$ for 1 month (1M) \\
2 & DS & MA & NT, SB, PA, SP & $\begin{array}{l}\text { In water at } 37^{\circ} \mathrm{C} \text { for } 1 \text { month }(1 \mathrm{M}) \text {, and in } \\
\text { water at } 37^{\circ} \mathrm{C} \text { for } 3 \text { months before surface } \\
\text { treatment and for } 1 \mathrm{M} \text { after all curing } \\
\text { processes }(3 / 1 \mathrm{M})\end{array}$ \\
3 & DS, SO, EP & MA & SP & $\begin{array}{l}\text { In water at } 37^{\circ} \mathrm{C} \text { for } 1 \text { month (1M), } 1 \text { year } \\
(1 \mathrm{Y}) \text { and thermal-cycled in water between } \\
4^{\circ} \mathrm{C} \text { and } 60^{\circ} \mathrm{C} \text { for } 10,000 \text { cycles (TC) }\end{array}$ \\
\hline
\end{tabular}

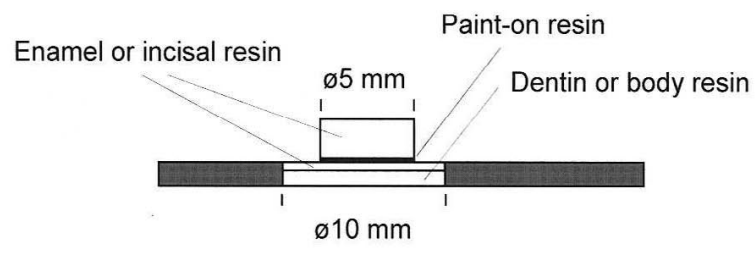

Fig. 1 The test specimen scheme for shear test.

of the crown \& bridge composites shown in Table 1 was uniformly applied, and then the paste surface made smooth with a plastic strip and a glass plate. After removing the glass plate, the paste surface was light-cured for 180 seconds with a light curing unit ( $\alpha$-LIGHT, Morita, Saitama, Japan). The cured surfaces of the enamel or incisal composites were then treated under the conditions shown in Table 2. Alumina powder with average particle size of $50 \mu \mathrm{m}$ was used for sandblaster treatment. The $\mathrm{c} \& \mathrm{~b}$ liquid was painted with an exclusive brush and dried for 30 seconds. The paint-on resin was painted in 0.2-mm thickness with an exclusive brush, and lightcured for 90 seconds with a light curing unit (Unix S, Heraeus Kulzer Japan, Osaka, Japan). The manufacturer's identical enamel or incisal composite was filled on the cured paint-on resin using a fluorocarbon resin mold with a hole $(\varnothing 5 \times 2 \mathrm{~mm})$ and light-cured for 180 seconds with the former light curing unit (Fig. 1). Three conditions for adhesive test are shown in Table 3: the test specimens for adhesive test were prepared by changing the paint-on resin in Condition 1, the surface condition in Condition 2, and the crown \& bridge composite in Condition 3.

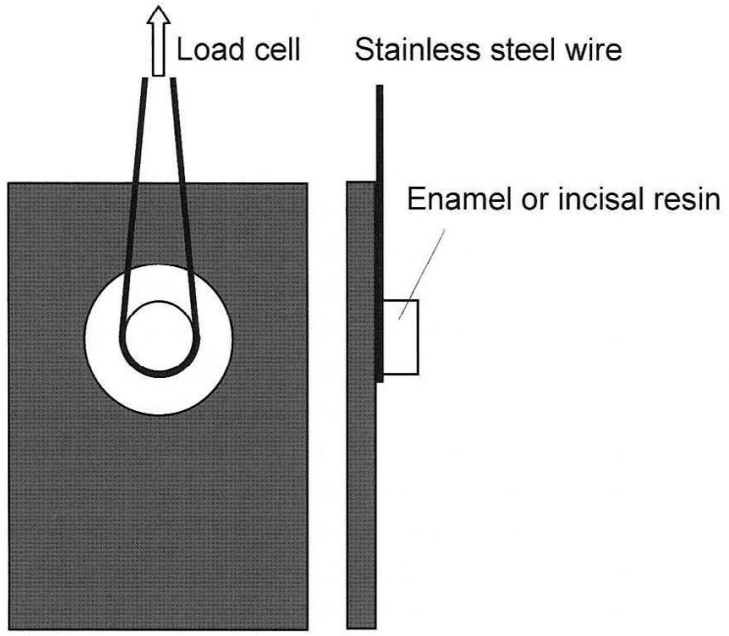

Fig. 2 The schematic representation of the shear test.

Adhesive strength measurement

After storage or thermal-cycling, the shear bond strengths (adhesive strengths) of test specimens were measured with a universal testing machine (TCM$1 \mathrm{kNNB}$, Minebea, Nagano, Japan) at a cross-head speed of $0.5 \mathrm{~mm} / \mathrm{min}$. A stainless steel wire with $0.43-\mathrm{mm}$ square was connected to a load cell and the stainless steel holder attached to the jig (Fig. 2).

\section{Fillers and monomers analyses}

Each paint-on resin was put into a porcelain crucible and weighed $\left(\mathrm{W}_{\mathrm{a}}\right)$ with an analytical balance. Then it was fired in electric furnace at $700^{\circ} \mathrm{C}$ for 6 hours, and the inorganic filler was weighed $\left(\mathrm{W}_{\mathrm{g}}\right)$ after it had cooled. The inorganic filler content $\left(\mathrm{W}_{\mathrm{g}} / \mathrm{W}_{\mathrm{a}}\right)$ was calculated and averaged for three samples. 
After weighing, the inorganic filler was fixed in a specimen holder and subjected to X-ray diffraction (XRD, Rint 2000, Rigaku, Tokyo, Japan). The diffraction conditions were $\operatorname{CuK} \alpha, 40 \mathrm{kV}-30 \mathrm{~mA}$, at a scanning rate of $2^{\circ} / \mathrm{min}$.

The paint-on resin paste was uniformly applied between two $\mathrm{KBr}$ plates and measured with Fourier transform infrared spectrometer (FTIR, FT/IR-460, JASCO, Tokyo, Japan).

\section{Statistical analysis}

Seven test specimens were used for the adhesive strength measurement. Two-way analysis of variance (ANOVA) was conducted with storing conditions and materials as the independent variables and adhesive strengths as dependent variables. The test specimens stored in water at $37^{\circ} \mathrm{C}$ for 1 day (1D) was used as control, and Tukey's test was carried out to analyze the difference.

\section{RESULTS}

The adhesive strengths measured under Condition 1 are shown in Fig. 3. The test specimens used three shades of paint-on resin (MA, MO, and MT), and their adhesive strengths ranged from 8.2 to $9.1 \mathrm{MPa}$. There were no statistical differences among the values of the paint-on resins, and between the values of $1 \mathrm{D}$ - and 1M-specimens ( $\mathrm{p}>0.05)$.

The adhesive strengths measured under Condition 2 are shown in Fig. 4. The adhesive strengths of 1D- and 1M-specimens under four surface treatment conditions (NT, SB, PA, and SP) ranged from 8.0 to $9.1 \mathrm{MPa}$, and no statistical differences were observed among the values of four surface treatments $(\mathrm{p}>0.05)$. The adhesive strengths of $3 / 1 \mathrm{M}$-specimens

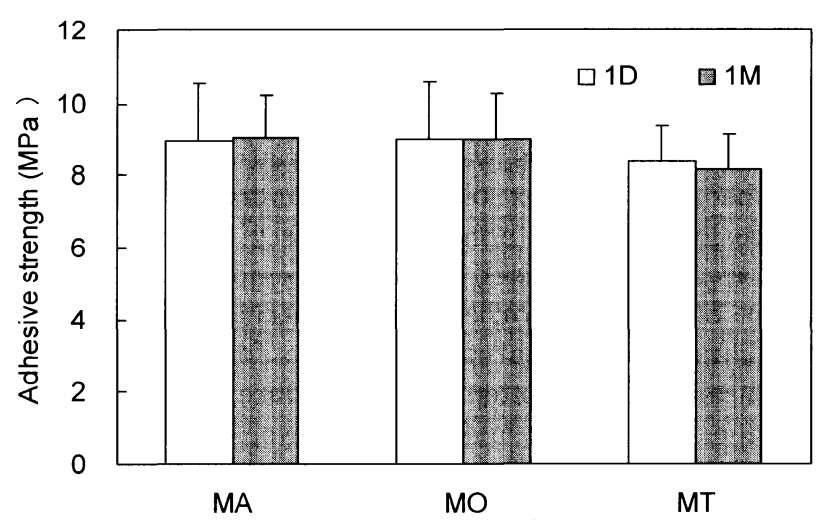

Fig. 3 Adhesive strengths between the crown and bridge composite (DS) and the three shades of paint-on resin ( $\mathrm{MA}, \mathrm{MO}$, and $\mathrm{MT}$ ), where $1 \mathrm{D}$ : stored in water at $37^{\circ} \mathrm{C}$ for 1 day, and $1 \mathrm{M}$ : stored in water at $37^{\circ} \mathrm{C}$ for 1 month. in $\mathrm{SB}$ and $\mathrm{SP}$ (8.3 and $8.4 \mathrm{MPa}$ ) were higher than those in NT and PA $(4.9$ and $6.1 \mathrm{MPa})(\mathrm{p}<0.01)$.

The adhesive strengths measured under Condition 3 are shown in Fig. 5. The 1D-, 1M-, and 1Yspecimens used three kinds of light-curing crown \& bridge composite (DS, SO, and $\mathrm{EP}$ ), and their adhesive strengths ranged from 9.0 to $9.4,8.9$ to 9.6 , and 6.0 to $7.1 \mathrm{MPa}$ respectively. No statistical differences were observed among the values of storing conditions $(p>0.05)$. However, the adhesive strengths of EP specimens decreased statistically compared with those of DS and SO specimens $(\mathrm{p}<0.05)$. No statistically significant differences were found between 1D-, 1M-, and $1 \mathrm{Y}$-specimens and thermal-cycled specimens (TC) $(p>0.05)$.

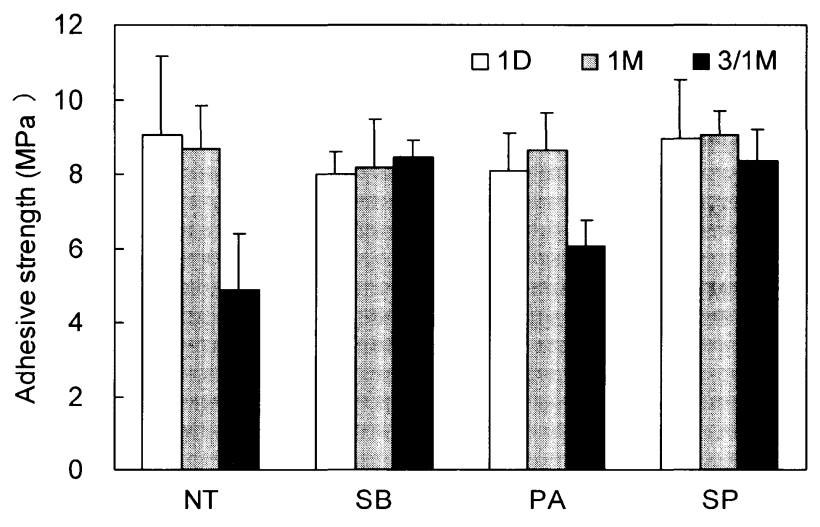

Fig. 4 Adhesive strengths between the crown and bridge composite (DS) and the paint-on resin (MA) under four surface treatment conditions (NT, SB, PA, and $\mathrm{SP})$, where 1D: stored in water at $37^{\circ} \mathrm{C}$ for 1 day, $1 \mathrm{M}$ : stored in water at $37^{\circ} \mathrm{C}$ for 1 month, and $3 / 1 \mathrm{M}$ : stored in water at $37^{\circ} \mathrm{C}$ for 3 months before surface treatment and for $1 \mathrm{M}$ after all curing processes.

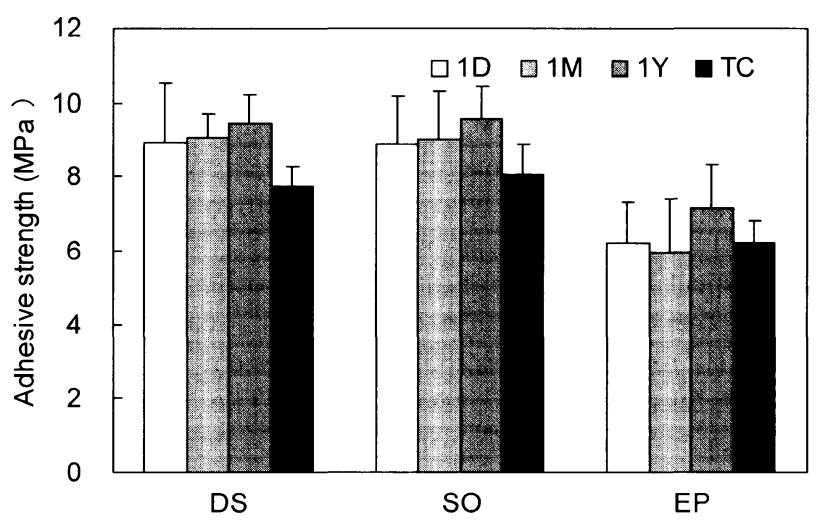

Fig. 5 Adhesive strengths between the crown and bridge composite (DS, SO, and EP) and the paint-on resin (MA), where $1 \mathrm{D}$ : stored in water at $37^{\circ} \mathrm{C}$ for 1 day, $1 \mathrm{M}$ : stored in water at $37^{\circ} \mathrm{C}$ for 1 month, $1 \mathrm{Y}$ : stored in water at $37^{\circ} \mathrm{C}$ for 1 year, and TC: thermalcycling in water between at $4{ }^{\circ} \mathrm{C}$ and at $60^{\circ} \mathrm{C}$ for 10,000 cycles. 


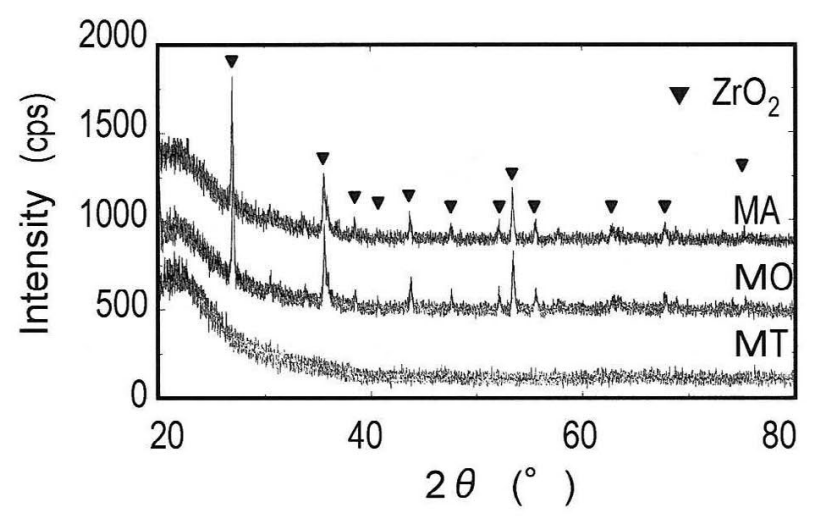

Fig. 6 X-ray diffraction patterns of the inorganic filler of three shades of paint-on resin $(\nabla$ in $\mathrm{MA}$ and $\mathrm{MO}$ corresponds to $\mathrm{ZrO}_{2}$ ).

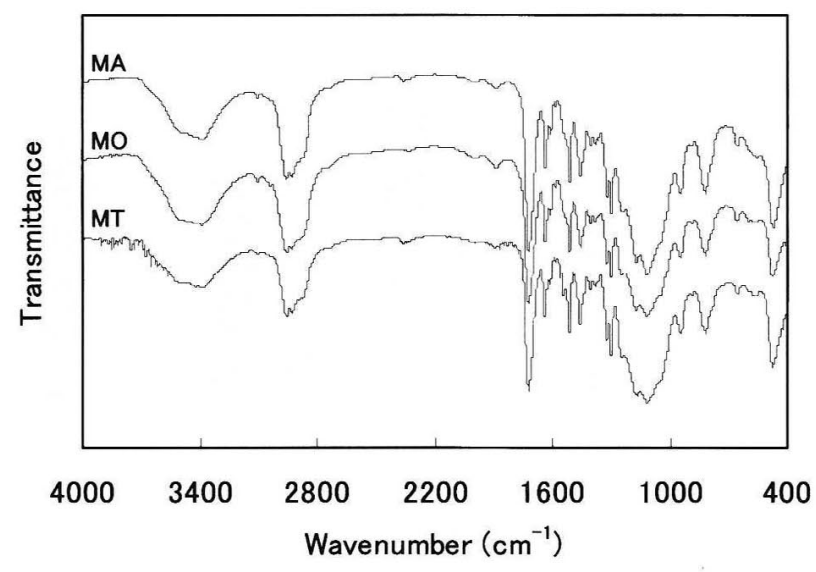

Fig. 7 FTIR spectra of three shades of paint-on resin before curing.

The inorganic filler contents of MA, MO, and MT were $37.9 \%, 39.0 \%$, and $35.9 \%$ respectively. The XRD patterns of the inorganic fillers are shown in Fig. 6. The mark ( $\boldsymbol{\nabla}$ ) in MA and MO corresponds to $\mathrm{ZrO}_{2}$ peak, and broad patterns corresponding to amorphous material were observed in all three.

FTIR spectra are shown in Fig. 7. MA, MO, and MT spectra were similar to each other. Since the characteristic absorption of $1533 \mathrm{~cm}^{-1}$ corresponds to $\delta \mathrm{N}-\mathrm{H}$, and those of 1608 and $1509 \mathrm{~cm}^{-1}$ correspond to benzene, paint-on resins should be composed of UDMA- and Bis-GMA- or Bis-MEPP-type monomers.

\section{DISCUSSION}

For the test specimens which used three shades of paint-on resin (MA, MO, and $\mathrm{MT}$ ), there were no statistical differences among their adhesive strength values $(p>0.05)$. This being so because there was hardly any difference in the filler content and in the filler and monomer compositions. The dental

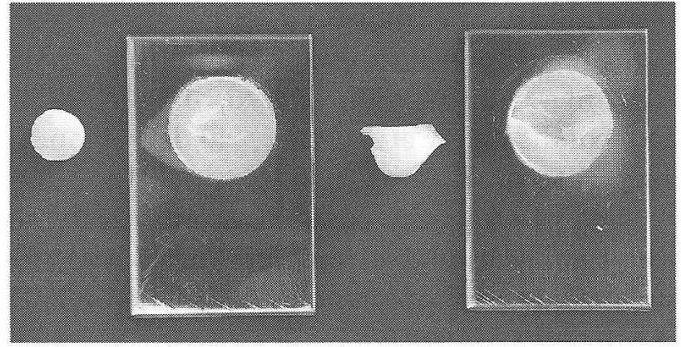

Fig. 8 Fractured test specimens after the shear test (left: interface fracture of the $3 / 1 \mathrm{M}$ specimen in NT of Fig. 4; right: cohesive fracture of the $1 \mathrm{Y}$-specimen in $\mathrm{EP}$ of Fig. 5).

composite resin cures by radical polymerization. Therefore when oxygen exists, free radicals formed from an initiator are scavenged and the nonpolymerized monomer remains on the surface. An incremental method using this non-polymerized monomer is widely used for composite resins and crown \& bridge composites. Bagis et al. ${ }^{12)}$ reported that a heat treatment at $50-125^{\circ} \mathrm{C}$ significantly decreased the amount of non-polymerized monomer remaining in a post-light-cured composite resin. This fact shows that non-polymerized monomer - which is required for polymerization - remains primarily in the surface layer.

In $\mathrm{SB}$, the non-polymerized monomer in the surface layer was removed with a sandblaster. As a result, there were no statistical differences in adhesive strength between SB and NT specimens (Fig. 4). In the same fig., the adhesive strengths of $3 / 1 \mathrm{M}-$ specimens in NT and PA significantly decreased compared with those of $1 \mathrm{D}$ - and $1 \mathrm{M}$-specimens in $\mathrm{NT}$ and PA. These specimens exhibited interface fracture between paint-on resin and the crown \& bridge composite (Fig. 8, left). When specimens are stored in water, little by little the monomer near the surface dissolves into the water, and the moisture penetrates into the void. It is well known that absorbed water in the resin matrix obstructs monomer infiltration, hence lowering the adhesive property. The sandblaster treatment is well used to remove the surface layer of water-absorbed resin matrix. As a result, the sandblaster treatment leads to formation of mechanical holding, extension of surface area, and generation of a fresh surface. However, Tachii et al. ${ }^{13)}$ mentioned that the rough surface by sandblaster treatment resulted in no adhesive strength increase because the composite paste has high viscosity. In the present study, the increase in adhesive strength was probably obtained due to a sufficient wetting effect - the viscosity of paint-on resin being lower than that of composite resins. These results showed that if the elapsed time following specimen production were short, sufficient adhesive strength can be 
obtained without extra labor (such as painting of the c \& b liquid).

When comparing among the types of light-curing crown \& bridge composite, the adhesive strength in EP was lowered significantly $(\mathrm{p}<0.05)$. However, cohesive fracture was sustained in the entire crown \& bridge composite (Fig. 8, right). Miyairi et al. ${ }^{14)}$ measured the adhesive strengths of composite resins and resin cements, and reported that when compared to resin cement, the composite resin became insensitive to stress concentration due to relaxation. Filler content and filler size of the composite resin would influence this factor.

The adhesive strengths of 1D- and 1M-specimens were not significantly different from those of TCspecimens $(p>0.05)$, hence highlighting the excellent durability of the paint-on resins' adhesive property. The 10,000 times' thermal-cycling test used in this investigation - which corresponds to two-and-a-half years in the oral cavity by Miyazaki et $a l^{15)}$ - is a considerably severe test condition. Generally, degradation induced by thermal-cycling is attributed to internal stress caused by the repetitions of expansion and contraction. The internal stress then generates a crack between filler and resin matrix, and soon after water penetrates into the crack. Low filler content and small filler size would delay the degradation of paint-on resin.

The XRD study revealed that MA and MO contained $\mathrm{ZrO}_{2}$ and amorphous material, whereas MT contained amorphous material only (Fig.6). $\mathrm{ZrO}_{2}$ is widely used as a colorant. Since MA and MO were colored and MT was superior in transparency, $\mathrm{ZrO}_{2}$ was probably added as a colorant in these pastes. Arikawa et $a l .{ }^{10)}$ reported that the optical transparency of MA and MO was lower than that of MT, and that it greatly decreased with increase in thickness. This property is most likely influenced by the diffusion of inorganic filler.

The filler content of paint-on resins ranged from 35.9 to $39.0 \%$. The previous study ${ }^{8)}$ also reported similar values: $37.8 \mathrm{wt} \%$ in MA, $38.8 \mathrm{wt} \%$ in $\mathrm{MO}$, and $36.1 \mathrm{wt} \%$ in MT. In addition, the three shades of paint-on resin (MA, MO, and MT) showed similar FTIR spectra (Fig. 7) - which meant that the same monomer types were used. These facts thus indicated that no difference in the filler and monomer contents of paint-on resins would affect adhesive strength and physical properties after curing.

This study has proved that there were no significant adhesive strength differences among the three shades of paint-on resin (Fig. 3) and among the three kinds of crown \& bridge composite (Fig. 5). In practical clinical service, the surface color of crown \& bridge composites post-restoration may be changed by some conditions. Assuming that these conditions exist, the adhesive strengths of the crown \& bridge composites stored in water for 3 months were measured before painting the paint-on resin $(3 / 1 \mathrm{M})$. It was shown through this study that by creating a new surface with sandblaster treatment, sufficient adhesive strength was obtained.

\section{ACKNOWLEDGEMENTS}

The authors are indebted to Heraeus Kulzer Japan Co. Ltd. for providing the materials used in this work.

\section{REFERENCES}

1) Lee YK, El Zawahry M, Noaman KM, Powers JM. Effect of mouthwash and accelerated aging on the color stability of esthetic restorative materials. Am J Dent 2000; 13: 159-161.

2) Koishi Y, Tanoue N, Matsumura H, Atsuta M. Color reproducibility of a photo-activated prosthetic composite with different thicknesses. J Oral Rehabil 2001; 28: 799-804.

3) Suese K, Kawazoe T. Wear resistance of hybrid composite resin for crown material by the two-body sliding test. Dent Mater J 2002; 21: 225-237.

4) Doray PG, Eldiwany MS, Powers JM. Effect of resin surface sealers on improvement of stain resistance for a composite provisional material. J Esthet Restor Dent 2003; 15: 244-250.

5) Duymus Z, Orbak R, Dilsiz A. Abrasion resistance of veneering materials to tooth brushing. Dent Mater $J$ 2003; 22: 460-466.

6) Johnston WM, Reisbick MH. Color and translucency changes during and after curing of esthetic restorative materials. Dent Mater 1997; 13: 89-97.

7) Stober T, Gilde H, Lenz P. Color stability of highly filled composite resin materials for facings. Dent Mater 2001; 17: 87-94.

8) Fujii K, Ban S, McCabe JF. Toothbrush abrasion of paint-on resins for shade modification of crown and bridge resins. Dent Mater J 2003; 22: 244-250.

9) Fujii K, Arikawa H, Kanie T, Ban S. Toothbrush abrasion of paint-on resins for shade modification and crown resins: Effect of water absorption. Dent Mater J 2004; 23: 223-229.

10) Arikawa H, Kanie T, Fujii K, Homma T, Takahashi H, Ban S. Optical properties of paint-on resins for shade modification of crown and bridge resins - Light transmittance characteristics. Dent Mater J 2003; 22: 272-279.

11) Arikawa $H$, Kanie $T$, Fujii $K$, Ban S, Homma $T$, Takahashi H. Optical and color stabilities of paint-on resins for shade modification of restorative resins. Dent Mater J 2004; 23: 155-160.

12) Bagis $\mathrm{YH}$, Rueggeberg FA. The effect of post-cure heating on residual, unreacted monomer in a commercial resin composite. Dent Mater 2000; 16: 244-247.

13) Tachii D, Takahashi Y, Habu T, Shimizu H, Koyanagi $\mathrm{S}$. Bond strength of visible light-cured resin composite bonded to occlusal surface of abrasion-resistant plastic posterior tooth. J Jpn Prosthdont Soc 1998; 42: 574- 
579.

14) Miyairi H, Fukuda H. A shear test method of dental adhesives. J J Dent Mater 1987; 6: 614-620.

15) Miyazaki T, Suzuki E, Miyaji T. The influence of thermal cycling on the mechanical properties of posterior restorative composite resins. J J Dent Mater 1986; 5: 187-195. 